Original Article

\title{
Early signs of physical overstrain of the cardiovascular system in athletes with symptoms of connective tissue dysplasia
}

\author{
OLEG NEKHANEVYCH $^{1}$, VIKTORIIA BAKURIDZE-MANINA ${ }^{2}$, VIACHESLAV KHOMENKO ${ }^{3}$ \\ ${ }^{1,2,3}$.Physical rehabilitation, sports medicine and valeology department, State Establishment "Dnipropetrovsk \\ Medical Academy of the Ministry of Health of Ukraine", UKRAINE
}

Published online: July 31, 2018

(Accepted for publication July 2, 2018)

DOI:10.7752/jpes.2018.s2171

\begin{abstract}
In some cases, individuals with the signs of connective tissue dysplasia, in particular with small abnormalities of the development of the heart are allowed to take sports. The purpose of the study was to improve the medical and pedagogical support of the training process of athletes with signs of connective tissue dysplasia by substantiating the early criteria of acute physical overstrain of the cardiovascular system. 247 athletes were examined, 59 of them with signs of systemic involvement of connective tissue in the dysplastic process. The medical criteria for admission and the planning of training-competitive loads in athletes are established, taking into account the influence of external and visceral signs of connective tissue dysplasia on the functional state of the organism. Early signs of overstrain of cardiac function during exercise of athletes with signs of connective tissue dysplasia were symptoms of disturbance of myocardial relaxation by the indicators of diastolic function of the heart, therewith the ejection fraction at rest can be maintained at normal levels. The presence of signs of connective tissue dysplasia in athletes with different predicted states requires sports doctors and trainers to conduct in-depth analysis and differential diagnostics of clinical forms in order to prevent complications during trainingcompetitive loads.
\end{abstract}

Key Words: early signs of physical overexertion, small abnormalities of the heart.

\section{Introduction}

When solving the issues of admission and planning of training-competitive loads, a special interest is caused by the individuals with the signs of connective tissue dysplasia (CTD). Under the CTD they understand the inherited connective tissue disorders that are united in syndromes and phenotypes based on the community of external and/or visceral signs and are characterized by genetic heterogeneity and diversity of clinical manifestations from benign subclinical forms to the development of multiple organ and multiple system pathology with progressive course (1). The main features of these disorders are: prevalence, progredient course, multiorgan character of the lesion and not infrequently the adverse outcome of this pathology. The most common signs of CTD are musculoskeletal anomalies, mitral valve prolapse (MVP) and that of other valves, aneurysms of the aorta and large vessels, additional (abnormal) tendon cords (ATC) (2). Most authors attach a secondary importance to these dysplastic-dependent changes in the heart and major vessels, in the development of sudden cardiac death (SCD) in sports $(3,4)$. But having analyzed literary sources we found that in the aggregate, this group of causes makes up about $10-15 \%$ of SCD cases in sport. So, in the general structure of sudden death in sport myxomatous degeneration of the mitral valve leaflets was found in $2-3 \%$, the rupture of the aortic aneurysm - in 3-3.1\%, pathological curvature of the coronary arteries - in $2.5-13.7 \%(4,5)$. In addition, the attention is paid to a large number of small heart abnormalities that are diagnosed as findings in case of SCD. This is confirmed by the data obtained on the sectional material of the died suddenly in acute left ventricular failure: the marginal areas of sclerosis and hyalinosis with thickening of the valve valves were found in $23 \%$, MVP $-4 \%$, tricuspid valve prolapse $-3 \%$, ATC $-11 \%$, thickening of the separate ventricular chords $-3 \%$, reduction of the number of chords $-5 \%$, extension of the aortic root $-19 \%$, pathological curvature of the aorta and coronary vessels $-21 \%$ (6). According to (GI Nechayeva et al., 2007) about $20 \%$ of the dead suddenly due to cardiac symptoms experienced SCD manifestations CTD patients makes up 5.8 per 1000 per year (7).

Thus, the presence of CTD signs in different predicted states requires sports doctors and trainers to conduct indepth analysis and differential diagnosis of clinical forms in order to prevent complications during trainingcompetitive loads.

In some cases, individuals with such changes as prolapse of valves and ATC of the cardiac ventricles are allowed to sporting activities [3,8]. Moreover, in some sports, people who have different phenotypic manifestations of CTD (high growth and enlargement of arm span - for rowing, volleyball and basketball, asthenic constitution and hypermobility of joints - for rhythmic and artistic gymnastics and synchronized swimming) are selected purposefully. [3, 9]. 
With all the diversity of lesions to organs and systems in CTD patients, the leading pathology that determines the quality and prognosis of life is cardiovascular disorders $(1,7,10)$. In the literature there are some publications about the possibility of SCD onset at certain nosologies, such as Marfan syndrome $(11,12)$ and MVP $(11,13$, 14). Unfortunately, most researchers, trainers and sports physicians rarely take into account objective data on changes in the state of the heart and hemodynamic shifts during loads of varying power, especially in athletes with CTD. The single works in this direction mainly reveal the degree of shift of the indicators of a global systolic function of the heart in athletes with the CTD only as a result of the long-term effect of physical activity at rest during stage medical examinations (15). The changes of hemodynamics in the heart of athletes, in particular with CTD, when performing physical activity of different intensity are elucidated insufficiently.

Therefore, the study of mechanisms and ways of adapting the heart of athletes with CTD in conditions of increased hemodynamic loading, that is, during sports training, is an urgent and up to date scientific task.

The aim of the study was to improve the medical and pedagogical support of the training process of athletes with signs of connective tissue dysplasia by substantiating the early criteria of acute physical strain of the cardiovascular system.

\section{Material \& methods}

In order to solve the tasks set, we examined 247 athletes aged 7 to 40 years (average age was 16.1 \pm 5.9 years), of them $65.2 \%$ were men and $34.8 \%$ - women. At the onset of the survey, athletes had a sporting experience of $7.5 \pm 5.0$ years. The average duration of training sessions per week was $15.0 \pm 9.8$ hours. The study included athletes-begginners without athletic title (25.1\%), athletes of II (23.9\%) and I title (17.8\%), as well as athletes-professionals, memebers of regional and national teams (candidates master of sports $-16.2 \%$, masters of sports $-13.4 \%$ and international masters of sports $-3,6 \%$.

With the help of anthropometry and somatoscopy, signs of systemic involvement of connective tissue (SICT) in the dysplastic process were determined: the Kettle index was calculated, and the signs of dolichostenomelia were determined by calculating the ratio of the length of the hand, foot, the arm span to the growth, and the ratio of the upper segment of the trunk to the lower one (1). The degree of hypermobility of the joints was assessed using the 9-point scale of P.Beighton (16). Also, the condition of the foot arch, the presence of deformities of the spine, chest, skull and limbs was assessed, skin extension and the presence of strias, hernias and vascular pigmentation were assessed as well. Each positive feature was assigned a certain number of points in accordance with the methodology, point total greater than 11 points was considered to be diagnostically significant (1).

In a state of physiological rest, an electrocardiographic and echocardiographic (EchoKG) examination of athletes was carried out according to the standard protocol $(17,18)$. The diastolic function of the left ventricle (LV) was evaluated by the values of the transmitral flow in pulsed wave dopplerography and the velocity of the fibrous ring of the mitral valve in its lateral part in tissue dopplerography in accordance with the recommendations of the European Echocardiographic Association (19). By the results of anthropometry and echocardiography, athletes with CTD - 59 people were selected (main group). The control group consisted of 188 athletes without the indicated signs. After that, the patients performed a load on the vertical bicycle ergometer "Ketler X1" with stair-stepped increase in load without rest periods. The initial load was selected based on the weight of the patient and was equal to $1 \mathrm{~W} / \mathrm{kg}$. The load on each step increased by $1 \mathrm{~W} / \mathrm{kg}$ and lasted for 2 minutes. Criteria for termination of loading were clinical, functional or electrocardiographic absolute indications for cessation of loading according to the recommendations of the American Heart Association (20). At the end of each load, EchoKG was performed: the dynamics of the ejection fraction and the systolic shortening of the lungs in the parasternal position along the long axis of the heart, the magnitude of the transmitral flow and the movement of the mitral valve fibrous ring in the four-chamber apical position were evaluated. In the recovery period from the 3rd to 5th minute, an electrocardiographic and echocardiographic examination was performed according to standard methods. All athletes had an EchoKG test on the Philips HDI 5000 apparatus (manufactured in the USA, 2004) using 2-4 MHz phase sensor in 2D, M, color, pulse-wave and continuous-wave Doppler modes. method (21).

To determine physical performance, athletes were tested by PWC170 on a bicycle with a standard

Statistical processing of the obtained results was carried out using the package of licensed applications STATISTICA (6.1, serial number AGAR909E415822FA) (22). The type of distribution of indicators was analyzed using the Shapiro-Wilk's W-test. The reliability of differences between indicators were defined considering the type of distribution, using Student's t-criterion and the Mann-Whitney U-criterion. The ANOVA/MANOVA dispersion analysis was used to determine the influence of the investigated factors on the study groups. The threshold level of statistical significance of the obtained results was $p<0,05$. The results are presented as $\mathrm{M} \pm \mathrm{SD}$.

The work was carried out in compliance with the regulations of the medical ethics committee developed in compliance with provisions of the European Convention "On protection of human dignity in biomedical perspective" (1997) and the Helsinki Declaration of the World Medical Association (2008). 


\section{Results}

Of SICT signs in the group of athletes with CTD, the most often there were observed lack of body weight, dolihostenomelia, hypermobility of joints and flat foot as shown in table 1.

Table 1. Frequency of external manifestations of connective tissue dysplasia in a group of athletes

\begin{tabular}{|l|l|c|}
\hline № & \multicolumn{1}{|c|}{ Indexes } & Athletes with CTD $(\mathrm{n}=59)$ \\
\hline 1 & Lack of body weight & $33,9 \%$ \\
\hline 2 & Dolichostenomelia & $37,2 \%$ \\
\hline 3 & Hypermobility of joints & $66,1 \%$ \\
\hline 4 & Funnel chest & $13,6 \%$ \\
\hline 5 & Pigeon chest & $20,3 \%$ \\
\hline 6 & Scoliosis & $30,5 \%$ \\
\hline 7 & Kyphosis & $8,5 \%$ \\
\hline 8 & Increased expansion of the skin & $22,0 \%$ \\
\hline 9 & Hernias (inguinal, umbilical) & 0 \\
\hline 10 & Skin strias & $15,3 \%$ \\
\hline 11 & Flat foot & $50,8 \%$ \\
\hline
\end{tabular}

To establish the difference in the comparison groups on the state of cardioghemodynamics, we conducted a one-way ANOVA, where as a group factor, the presence of signs of CTD was selected, and the dependent factors were the state of the systolic function of the left ventricle (by the indicator of the ejection fraction of the left ventricle (EF) and the diastolic function of the left ventricle (by the indicator the ratio of the maximum speed of the early diastolic filling of the left ventricle and the maximal tissue velocity of the early diastolic displacement of the mitral valve ring (E/e') as shown in table 2.

Table 2. Level of systolic and diastolic function of the left ventricle of the heart at rest, (M \pm SD )

\begin{tabular}{|l|l|c|c|c|}
\hline № & \multicolumn{1}{|c|}{ Index } & Athletes with CTD,$(\mathrm{n}=59)$ & Athletes without CTD, $(\mathrm{n}=188)$ & $\mathrm{P}$ \\
\hline 1 & $\mathrm{FV}, \%$ & $63.3 \pm 10.1$ & $66.0 \pm 11.4$ & 0.1 \\
\hline 2 & E/e', units & $6,27 \pm 1,54$ & $5,69 \pm 1,78$ & 0.01 \\
\hline
\end{tabular}

In cyclergometry there was found deterioration of myocardial relaxation during diastole in the athletes of the main group when performing loads of average capacity, which led to the drop in EF at submaximal level as shown in table 3. This was not revealed in the athletes of the control group.

Table 3. Dynamics of indices of systolic and diastolic function of athlete's heart at physical activity of different power $(\mathrm{M} \pm \mathrm{SD})$

\begin{tabular}{|c|l|c|c|c|c|c|}
\hline \multicolumn{2}{|c|}{ Indexes } & \multirow{2}{*}{ Rest state } & \multicolumn{4}{c|}{ Level of load } \\
\cline { 4 - 7 } & & $1 \mathrm{~W} / \mathrm{kg}$ & $2 \mathrm{~W} / \mathrm{kg}$ & $3 \mathrm{~W} / \mathrm{kg}$ & $4 \mathrm{~W} / \mathrm{kg}$ \\
\hline \multirow{2}{*}{$\begin{array}{c}\text { Main group } \\
\mathrm{n}=59\end{array}$} & $\mathrm{EF}, \%$ & $63,3 \pm 10,1$ & $74,4 \pm 19,9$ & $75,1 \pm 14,2$ & $73,1 \pm 8,3^{*}$ & $72,3 \pm 4,9^{*}$ \\
\cline { 2 - 7 } & E/e', units & $6,27 \pm 1,54^{*}$ & $7,90 \pm 1,86^{*}$ & $8,32 \pm 2,00^{*}$ & $10,5 \pm 2,7^{*}$ & $15,7 \pm 4,3^{*}$ \\
\hline \multirow{3}{*}{$\begin{array}{c}\text { Control group } \\
\mathrm{n}=188\end{array}$} & $\mathrm{EF}, \%$ & $66,0 \pm 11,4$ & $70,1 \pm 3,0$ & $74,2 \pm 7,1$ & $78,7 \pm 6,9$ & $78,6 \pm 6,0$ \\
\cline { 2 - 7 } & E/e', units & $5,69 \pm 1,78$ & $5,06 \pm 1,21$ & $5,39 \pm 1,20$ & $5,46 \pm 1,31$ & $7,26 \pm 7,03$ \\
\hline
\end{tabular}

Note. ${ }^{*}-\mathrm{p}<0,05 . \mathrm{EF}-$ left ventricle ejection fraction, $\mathrm{E}$ - maximum speed of early diastolic filling of left ventricle, e'- maximum speed of early diastolic motion of mitral valve fibrous ring.

Studying the state of cardiohemodynamic in the period of restitution, an extension of the recovery time in athletes with CTD was established. Thus, 3 minutes after the load performing in the representatives of the main group, EF was at the level of $68.1 \pm 15.2 \%$, and the ratio E/e' was $10.5 \pm 2.7$ units, which statistically differed from the comparison group, where they amounted to $62.0 \pm 6.2 \%$, and the ratio E/e' was $5.63 \pm 1.71$ units.

The indices of the functional state of athletes were chosen as the measure of the total impact of the above differences in the comparison groups. To determine the impact of SICT on the physical capacity of athletes, we conducted a one-way ANOWA, where the level of SICT more than 11 points was chosen as a group factor, and the level of physical capacity was as dependent factor as shown in table 4.

Table 4. The level of physical performance in the comparison groups, $(\mathrm{M} \pm \mathrm{SD})$

\begin{tabular}{|l|c|c|c|c|}
\hline № & Index & Athletes with CTD, $(\mathrm{n}=59)$ & Athletes without CTD, $(\mathrm{n}=188)$ & P \\
\hline 1 & Physical capacity, W / kg & $2,79 \pm 0,85$ & $3,1 \pm 0,79$ & 0,01 \\
\hline
\end{tabular}




\section{Dicussion}

Results of the study of the degree of myocardium relaxation in the process of performing physical activity in the group of athletes without CTD signs coincide with the data of the international researches and indicate that under the loads of medium at submaximal capacity the speeds of $\mathrm{E}$ and $\mathrm{e}^{\prime}$ in the norm increase proportionally (23). Thus, the E/e' ratio remains unchanged or reduces insignificantly. In individuals with the impaired myocardial relaxation with the increase in the load, the increase of e' is less than E, which leads to the increase in the E/e' ratio, observed in the group of athletes with CTD signs in our study.

Violations of myocardial relaxation at the average level of load led to the drop in the pumping function of left ventricle in athletes with CTD at the next degree of intensity of the load, which did not occur in the control group athletes. This proves the possibility of using as the early signs of overexertion of cardiac activity symptoms of disturbance of myocardial relaxation, that is, of diastolic function of the heart, while in such patients, the resting state can remain at normal level. These results coincide with the data of scholars who studied patients with heart failure (24).

Data on the reduction of physical performance indices in patients with CTD signs in general coincide with the data of other authors who worked in this direction $(25,26)$, and basically prove the possibility of considering SICT in the dysplastic process while arranging training-competitive loads of athletes

\section{Conclusions}

The presence of signs of connective tissue dysplasia in athletes at different predicted conditions requires sports doctors and trainers to conduct in-depth analysis and differential diagnostics of clinical forms in order to prevent complications during training-competitive loads.

Early signs of overstrain of cardiac activity during exercise of athletes with signs of connective tissue dysplasia were symptoms of disturbance of myocardial relaxation by the indicators of diastolic function of the heart, therewith the ejection fraction at rest can be maintained at normal levels.

Increase of the ratio of the maximum speed of early diastolic filling of the left ventricle and the maximum tissue speed of the early diastolic displacement of the mitral valve ring more than 8.0 units in the athletes with signs of connective tissue dysplasia during exercise, led to the drop of the pumping function of the left ventricle and, as a consequence, a decrease in the level of physical capacity. As such, in this group there was an extension of the recovery time after exercise. This should be taken into account when deciding the issues of admission and arranging training loads for such athletes.

Conflicts of interest - We haven't conflicts of interest.

\section{References:}

Kaduryna, T.Y., Gnusaev, S.F., Abbakumova, L.N., et al. (2014). Heritable and multifactorial disorders of connective tissue in children. Diagnostic algorithms, tactic. Pediatrics, 93(5), 1-40.

Evtushenko, S.K. Lisovskiy, E.V., Evtushenko, O.S. (2009). Connective tissue dysplasia in neurology and paediatrics (clinic, diagnostic and treatment). Manual to physicians. Donetsk, Ukraine: publisher Zaslavskiy A.Y., 372.

Smolensky, A.V., Myhajlova, A.V. (2007). Main directions of development of sports medicine at the present stage. Sports medicine, 2, 3-9.

Maron, B.J., Pelliccia, A. (2006). The heart of trained athletes: cardiac remodeling and the risks of sports, including sudden death. Circulation, 114 (15), 1633-1644.

Makarova, G.L. (2002). A practical guide for sports physicians. Rostov-na-Donu, Russia: «Publishing house BARO-PRESS», 800.

Nekhanevich O.B., Voichenko V.V. (2013). The analysis of sudden cardiac death cases among young persons in the Dnepropetrovsk region. Morphology, 7 (2), 61-65.

Nechaeva, G.I. Viktorova I.A. (2007). Connective tissue dysplasia: the terminology, diagnosis, tactics. Omsk, Russia: Publishing house "Printing Blanc-Kom", 188.

Bonow, R.O., Cheitlin, M., Crawford, M., Douglas, P.S. (2005). 36th Bethesda Conference: recommendations for determining eligibility for competition in athletes with cardiovascular abnormalties. J. Am. Coll. Cardiol., 14, 1334-40.

Garcia-Campayo, J. (2011). Joint hypermobility and anxiety: the state of the art. Curr. Psychiatry Rep, 13 (1), 18-25.

Pearson G., Devereux R., Loeys B., et al. (2008). Report of the National Heart, Lung, and Blood Institute and National Marfan Foundation Working Group on Research in Marfan Syndrome and Related Disorders. Circulation, 118 (7), 785-791.

Zemtsovsky, E.V., Malev, E.G., Luneva E.B. (2011). Hereditary connective tissue disorders, and sudden cardiac death. Herald arrhythmology, 63, 61-65.

Keane, M.G., Pyeritz, R.E. (2008). Medical management of Marfan syndrome. Circulation, 117, 2802-2813.

Osovska, N.Y., Serkova, V.K. (2007). Stratification of risk factors and treatment strategy of patients with mitral valve prolapse. Ukrainian medical journal, 2 (58), 78-83. 
Bonow, R.O., Carabello, B.A. Chatterjee, K., et al. (2006). ACC/AHA Guideline for the Management of Patient with Valvular Heart Disease. Circulation, 48, 1-148.

Krivolap, N.V. (2014). Dysplastic cardiopathy in football: characteristics of display depending on age, sex and sports experience. Sports medicine, 1, 95-101.

Beighton, P., Grahame, R., Bird, H. (2012). Hypermobility of Joints. New York: Springer, 204 p.

Kovalenko, V.M., Lutaj, M.I., Bratus', V.V., Viktorov, O.P., Voronkov, L.G., et al. (2009). Guide for cardiology. Kiev, Ukraine: MORION, 1368 p.

Evangelista, A., Flachskampf, F., Lancellotti, P., Badano, L., Aguilar, R., Monaghan, M., et al. (2008). European Association of Echocardiography recommendations for standardization of performance, digital storage and reporting of echocardiographic studies. Eur. J. Echocardiogr, 9(4), 438-448.

Nagueh, S.F., Appleton, C.P., Gillebert, T.C., Marino, P.N., Oh, J.K., et al. (2009). Recommendations for the evaluation of left ventricular diastolic function by echocardiography. Eur. J. Echocardiogr., 10, 165-93.

Fletcher, G.F., Ades, P.A., Kligfield, P., Arena, R., Balady, G.J., et al. (2013). Exercise Standards for Testing and Training: A Scientific Statement From the American Heart Association. Circulation, 128, 873-934.

Abramov, V.V., Klapchuk, V.V., Nekhanevich, O.B. Smirnova, O.L., Dzyak, G.V. (2014). Physical rehabilitation, sports medicine. Dnipropetrovsk, Ukraine: Gurfond, 455 p.

Halafyan, A.A. (2007). STATISTICA 6. The statistical analysis of the data]. Moscow, Russia: Open Company "Binom-press", $512 \mathrm{p}$.

Ha, J.W., Oh, J.K., Pellikka, P.A., Ommen, S.R., Stussy, V.L., Bailey, K.R., et al. (2005). Diastolic stress echocardiography: a novel noninvasive diagnostic test for diastolic dysfunction using supine bicycle exercise Doppler echocardiography. J Am Soc Echocardiogr, 18, 63-8.

Paulus, W.J., Tschope, C., Sanderson, J.E., et al. (2007). How to diagnose diastolic heart failure: a consensus statement on the diagnosis of heart failure with normal left ventricular ejection fraction by the Heart Failure and Echocardiography. Eur Heart J., 28, 2539-2550.

Kharitonova, L.G. (2010). Connective tissue dysplasia and its significance in the process of physical education and sports culture. Theory and Practice of Physical Culture, 7, 29-33.

Juul-Kristensen, B., Hansen, H., Simonsen, E.B., et el. (2012). Knee function in 10-year-old children and adults with generalised joint hypermobility. Knee, 19 (6), 773-8. 